\title{
Desenvolvimento profissional, profissionalidade e formação continuada de professores: possíveis contributos dos relatos autobiográficos profissionais
}

Mots clés: Développement professionnel des enseignants; Professionnalité; Récits de vie et formation continue

Luís Alcoforado*

Universidade de Coimbra

Resumo O debate sobre a contribuição das práticas de formação continuada para o desenvolvimento profissional e a construção da profissionalidade docente continuam no centro dos debates atuais sobre educação. Ao longo deste artigo, e, partindo de uma análise histórica e de um esclarecimento conceitual destas unidades de análise, procura-se trazer um olhar a partir das ciências da formação, problematizando a construção de uma proposta específica para a formação continuada dos professores, capaz de contribuir para uma ação transformadora ascendente, promotora de maior autonomia e responsabilidade, individual e coletiva. Debate-se, igualmente, a possibilidade dos relatos autobiográficos profissionais, se poderem assumir como uma dessas práticas formativas, apontando-se algumas condições de desenvolvimento, nomeadamente as dimensões interativa, dialógica e emancipatória, para que seja possível cumprir esse objetivo.

PalaVRas-Chave: Desenvolvimento Profissional dos Professores, Profissionalidade, Relatos autobigráficos e formação continuada.

\begin{abstract}
The debate about the contribution of continuing training practicesfor the professional development and for the construction of teachers'professionality remains in the centre of the actual debate on education. Throughout this study, starting from a historical analysis and a conceptual clarification of these units of analysis, we seek to bring a look from the training sciences perspective, questioning the construction of a specific proposal for the continuing training of teachers, enabling a contribution for an ascendant transforming action, promoting a larger autonomy and responsibility, individual and collective. It is equally debated the possibility of autobiographical stories professionals being able to assume as the one of these training practices, pointing up some development conditions, namely the interactive, dialogical and emancipatory dimensions, so that it is possible to fulfil that goal.
\end{abstract}

KEYWORDS: Teachers professional development, Professionality, Autobiographical stories and continuing training. 


\section{Introdução}

A partir do momento em que as escolas eclesiásticas assumiram a preparação de futuros oficiantes e, posteriormente, abriram-se à formação de jovens para a vida fora da Igreja, criaram o modelo do que haveria de se constituir como a escolaridade, o qual ainda hoje conhecemos. Com a emergência da modernidade, o Estado assumiu a organização e o controle da escola, acreditando ser necessário aproveitar a capacidade humana da educabilidade como forma indispensável para a consolidação de modelos de sociedade que acreditavam na superioridade ética da democracia em relação a outras formas de governo e na promoção continuada de desenvolvimento econômico, social e cultural. Na verdade, se todos devem participar nas escolhas políticas, sendo agentes de produção e transformação da cultura e assim, contribuir para a produção e a distribuição equilibrada da riqueza, era forçoso uma preparação que garantisse a aquisição dos saberes necessários para o envolvimento responsável numa cidadania ativa, incluindo o desempenho de diferentes papéis sociais.

Desta forma, a escola surgiu como uma instituição socializadora que interpretava, em cada momento e em cada sociedade, a herança cultural das gerações adultas, organizando-as em saberes hierarquizados e sequenciados, divididos por áreas disciplinares, transmitindo-os às crianças, adolescentes e jovens, esperando potencializar o seu desempenho futuro, enquanto cidadãos e trabalhadores. Tal transmissão baseava-se na convicção segura de que havia especialistas, quer no domínio desses saberes disciplinares, quer na forma de os comunicar, restando aos alunos acompanharem os ensinamentos e esforçarem-se no trabalho árduo da sua aquisição. Este especialista de saberes, saído da tradição do ensino escolástico, acabará por evoluir para um profissional, o Professor, titular de uma função na qual professa, ensina, expõe, disponibiliza os saberes conteudinais que são adquiridos pelos alunos unicamente como resultado dos seus esforços, condições, ou capacidades (ROLDÃO, 2005).

Sendo a escola assumida como responsabilidade do Estado, garantida, de forma direta ou indireta, por governos de diferentes orientações ideológicas e com diferentes entendimentos sobre os saberes a transmitir e a sua eventual associação a diferentes tipos de valores. O professor foi ficando sempre um pouco refém dessas opções políticas, assistindo, na generalidade dos casos, a uma clara limitação do controle que detém sobre os saberes a selecionar e sobre a sua autonomia nas formas de os transmitir. Esta desapropriação profissional foi-se constituindo, no entanto, associada a uma crescente complexificação dos desafios colocados à escola e à sua ação, pela generalidade dos agentes e instituições que com ela se relacionam.

É verdade que os questionamentos à função tradicional da escola começaram há mais de um século, em consequência do conhecimento produzido no âmbito das investigações sobre a aprendizagem e a educação, com destaque, entre outros contributos, para as reflexões de John Dewey e do movimento da Escola Nova (NÓVOA, 1997). Ao trazer os alunos para o centro do processo educativo, e, ao defender uma aprendizagem indissociavelmente ligada à vida, este movimento acaba por introduzir uma preocupação que obrigaria o Professor a assumir-se como mediador entre os alunos e os conteúdos, devendo considerar, também, os fins a que deviam conduzir essas aquisições. Meio século mais tarde, foi emergindo a convicção de que a escola é apenas um dos locais onde se aprende, sendo desafiada a conciliar a sua missão com uma conceção sincrônica (todos os espaços são potencialmente educadores) e diacrônica (a 
educação prolonga-se ao longo de toda a vida) das atividades educativas que o professor deverá conciliar numa dinâmica virtuosa. O último quarto de século, por sua vez, trouxe-nos a necessidade de compreender como cada um de nós constrói o seu próprio conhecimento e o significado que lhe atribuímos, conforme as nossas caraterísticas e as caraterísticas dos contextos onde agimos e interagimos (NÓVOA, 1997), obrigando os Professores a saberem lidar com a diversidade e a considerarem, os alunos, como agentes de uma realidade sociocultural em permanente (re)construção.

Contudo, a missão e as respostas que atualmente se atribui e se exigem da escola estão, elas próprias, em profunda transformação, nem sempre como consequência destas heranças e debates. Como referem Cordeiro, Alcoforado \& Ferreira (2012), o mandato que as sociedades contemporâneas atribuem às escolas passa pelo desafio de envolver todas as crianças, todos os adolescentes e todos os jovens, por muito mais tempo, procurando ensinar-lhes muitas coisas a mais, exigindo-lhes, de igual forma, que se abram às comunidades, devendo ser obrigadas a deixarem-se escrutinar por elas e preparando respostas mais condizentes com as suas exigências e necessidades. Sendo certo que muitas das reorientações impostas por essas vontades foram aparecendo ao longo das últimas décadas, quase sempre associadas a uma pressão que tende a incorporar discursos e práticas das ciências da gestão, mais orientadas por opções de eficiência e eficácia, do que as metas e os rankings são um eloquente exemplo, numa retórica e ação política de caráter mais neoliberal e neoconservador.

Então, se é verdade que, atendendo aos condicionalismos que foram definindo os contornos do seu desenvolvimento, assistimos, desde sempre, a um questionamento das características de verdadeira profissão da atividade de professor, hoje estamos perante um trabalho docente que não só é exercido junto de públicos cada vez mais heterogéneos e por vezes adversos, como se multiplicam os papéis e consequentes responsabilidades daqueles que o executam (ESTRELA, 2011). Todas estas constatações vêm obrigando à necessidade de se repensar a formação inicial para o exercício da atividade docente, mas apela, particularmente, à manutenção de um debate atualizado sobre as condições de desenvolvimento profissional a que elas obrigam, com as necessidades de formação continuada que lhes devem estar associadas.

Pretendem-se trazer, ao longo deste artigo, alguns contributos para esta reflexão! Primeiro, procuraremos esclarecer, numa perspetiva histórica e conceitual, o desenvolvimento profissional e a construção de uma profissionalidade para os professores, nas condições sociopolíticas predominantes, na atualidade, e nos desafios que a investigação vem colocando nos dias de hoje. Depois tentaremos trazer algumas reflexões do domínio das ciências da formação, inventariando o valor heurístico e explicativo de modelos teóricos especificamente pensados para a formação continuada, sublinhando os possíveis contributos que os relatos autobiográficos profissionais podem trazer para uma construção mais autônoma e responsável da profissionalidade docente.

\section{Desenvolvimento profissional e profissionalidade dos pro- fessores}

Desde, pelo menos, a alta Idade Média, que uma das etapas mais marcantes do processo de socialização dos indivíduos, na Europa continental, se traduz pela entrada no mundo de trabalho através do exercício de uma profissão. Mesmo quando os percursos formativos eram tão distintos como os das universidades, ou os das aprendi- 
zagens artesanais das oficinas medievais e as corporações tão diversas como os colégios profissionais, ou as casas dos ofícios, ter uma profissão implicava pertencer a um abrigo identitário, incorporado pelas pessoas e socialmente reconhecido, traduzindo uma construção simbólica eficaz, que os ritos sociais de acesso determinavam (DUBAR, 1997). Mais que transformar alguém num trabalhador, pertencer a uma corporação profissional, garantia-se a um cidadão a construção decisiva da sua identidade social, que ele assumia por inteiro, associando-a a qualquer processo de apresentação pessoal. Será necessário ter consciência, como nos lembra o mesmo autor, que estas identidades não são expressões psicológicas de personalidades individuais, nem produtos de estruturas econômicas que se impõem de cima, mas construções sociais que implicam a interação entre trajetórias individuais e sistemas de trabalho, emprego e formação.

O ingrediente profissional para a construção das identidades pessoais e sociais foi de tal forma estruturante que se manteve ao longo dos tempos como principal organizador dos processos de reconhecimento e relacionamento. No caso dos ofícios, após uma dupla desapropriação profissional, de saberes e identidade, ocorrida nas linhas tayloristas/fordistas da revolução industrial, as negociações laborais levaram, já na segunda metade do último século, ao acolhimento da vontade dos trabalhadores em readquirirem a sua identidade, agora, sob a forma da qualificação, com os percursos formativos e as convenções coletivas de trabalho que the foram associadas.

Para o caso da profissão, essa opção terminológica ficou sempre relacionada ao fato de alguém ter percorrido, com sucesso, um qualquer percurso formativo associado a níveis mais elevados de conhecimento sistemático, traduzido por um diploma socialmente valorizado, permitindo-lhe ser admitido por qualquer associação profissional como seu membro de pleno direito (ALCOFORADO, 2008). Este sentimento de pertença garantia, em simultâneo, uma alargada independência e capacidade de autorregulação da ação profissional, obrigando a um entendimento entre pares para a construção de um código ético do exercício da atividade profissional e para influenciar as condições de acesso a uma remuneração adequada.

Com um valor semântico de profissão, colocado nestes contornos conceituais e práticos, muitos autores discutem se poderemos, efetivamente, considerar a atividade de ensinar como configurando uma profissão, no sentido mais tradicional do termo. Por exemplo, Montero (2005) faz eco dessa hesitação geral, traduzindo-a pela ideia de que, na generalidade, a consideração do ensino como profissão e dos professores como profissionais foi, e continua a ser, um tema sujeito a controvérsia, uma vez que inclui dimensões de associação inquestionável ao entendimento mais ortodoxo de profissão, mas deixa vários contornos com traço muito pouco definido (LÜDKE \& BOING, 2004), em resultado (ROLDÃO, 2005) de uma construção histórica instável.

Por outro lado, como tem vindo a ser recorrentemente demonstrado, o entendimento mais clássico de profissão foi, ele próprio, questionado por interrogações de natureza diversa, ao longo das últimas décadas. Antes de mais, por razões políticas e econômicas, uma vez que os tempos mais recentes têm vindo a empurrar-nos para uma fragilização progressiva das dimensões mais coletivas das relações de trabalho em favor de relações e negociações mais individualizadas (ALCOFORADO, 2008). Mas as interpelações advêm, também, das próprias dinâmicas das atividades profissionais, quer seja por razões epistemológicas, dada a produção contínua e acelerada de 
conhecimento, quer seja por razões tecnológicas, uma vez que os meios e processos de produção de bens e prestação de serviços estão em constante mutação, quer seja, ainda, pela constante imprevisibilidade dos ambientes socioeconômicos que enquadram o desenvolvimento das atividades profissionais. Acrescem, a estas constatações, os contributos das ciências do trabalho, as quais nos têm vindo a demonstrar que o trabalho realizado difere sempre, em termos qualitativos e quantitativos, do trabalho previsto.

Também, por razões atribuíveis, a mudanças intra(inter)individuais, as conceções mais estaticistas de profissão começaram a revelar alguma insuficiência heurística e explicativa. Se, para alguns dos pensadores mais influentes do século XX, como por exemplo Jean Paul Sartre ou Ortega y Gasset, o Homem era projeto ou tarefa que levava toda a existência para ser realizada, os trabalhos de Carl Rogers e de Georges Lapassade, trouxeram-nos uma proposta de entendimento do ser humano como neotene, que se envolve permanentemente na construção e conquista de uma maturidade vocacional nunca atingida. Ainda, no domínio da Psicologia, as pesquisas sobre o desenvolvimento da identidade de Erikson, os ciclos da vida adulta de Levinson e os estádios de desenvolvimento do eu de Loevinger, obtendo forte repercussão junto da comunidade científica, acabaram por contribuir para a convicção generalizada que Baltes (1987) traduz pela ideia de que o desenvolvimento ao longo da vida é um longo processo de mudanças multidirecionais, entendidas como ganhos (crescimento) e/ou perdas (declínios), de plasticidade intra-individual, relacionada com as condições de vida e experiências, historicamente enquadradas nas condições socioculturais ao longo da vida.

Todos estes contributos nos impelem a entender que a vida profissional se constitui como uma articulação dinâmica de tempos e espaços que permitem aos profissionais (re)construírem, em permanência, as suas formas de ação, projetando, através delas, e em cada momento, todas as dimensões emocionais, utópicas, sociais e simbólicas que contribuem para a sua formação, sempre inacabada, enquanto pessoas. É esta ideia que, normalmente, traduzimos por desenvolvimento profissional: todo o conjunto de modificações e estabilidades (transformações e não transformações) que interferem no comportamento de uma pessoa, ao longo da sua vida profissional (ALCOFORADO, 2008). Para o caso dos Professores, esta ideia de desenvolvimento profissional tem vindo a constituir-se como uma unidade de análise de forte valor compreensivo (MARCELO, 2009) e, por isso mesmo, colocada no centro dos debates e trabalhos de pesquisa. Intuímos, então, que a atividade docente resulta da interação prolongada com todos os agentes, nos diferentes atos educativos e noutras formas de participação, gerando mudanças específicas na própria pessoa e nos contextos, resolvendo, em cada momento, de uma forma nem sempre equilibrada, a tensão constante entre ambas as partes.

Nesta lógica de debate, o Professor tem sido identificado (basta recordar os textos de, entre outros, Hargreaves), como um intelectual e prático reflexivo, cuja ação resulta, em cada momento, dos seus conhecimentos e competências, da compreensão de si mesmo e da interpretação que vai fazendo dos contextos onde atua (ESTRELA, 2011), promovendo o seu próprio desenvolvimento contínuo a partir de uma articulação pessoal de todas estas dimensões. No entanto, este nunca pode ser um percurso individualizado. Não o seria porque, como nos alertou Bakhtin (1993), cada um de nós se vê sempre através do olhar dos outros, mas não deve ser, também, porque como vem defendendo Morin (2002), é hoje mais urgente que nunca visar um 
entendimento de condição humana na articulação progressiva e harmoniosa de uma relação tripartida entre o indivíduo, a comunidade e a espécie humana, sem uma (des) valorização excessiva de cada um destes polos. Assim, retomar, ainda que no quadro de outras realidades socioeconômicas, o compromisso com o reforço das dimensões mais coletivas do trabalho é tão importante como valorizar os contributos mais individuais para essa construção.

Então, podemos concluir que os professores se encontram face à necessidade de continuarem a construir uma identidade profissional, num contexto de crise das profissões, tal como as conhecíamos. Se é verdade que esta construção tem acontecido sem que alguma vez tivessem vivenciado, na plenitude, a totalidade das dimensões que constituíam as profissões, no sentido mais tradicional do conceito, o desafio que se coloca é, ainda, por isso mesmo, mais necessário e aliciante. Procurando um desenvolvimento sustentável, baseado, em simultâneo, na autonomia individual e coletiva e na responsabilidade pela sua ação e pela promoção do bem-estar dos grupos de pertença, temos sido levados à tentativa de reabilitação do essencial da relação das pessoas com os seus grupos identitários e de todos com o trabalho, colocando, no centro desta busca, o conceito de profissionalidade.

Como observaram Courtois \& al. (1996), coloca-se profissionalidade ${ }^{1}$ no cerne da procura de uma recomposição das identidades profissionais, no trabalho e nas organizações, no âmbito de contextos caracterizados por estruturas descentralizadas, terciarização da economia, evolução e interdependência dos saberes, dinamismo e reconfiguração permanente das funções, valorização simultânea de interações e contribuições individuais e coletivas (Fig. 1). De uma forma complementar, mas mais ampla e dinâmica que a qualificação e a profissão que lhe servem de suporte histórico, a profissionalidade procura responder à complexidade, articulação e desenvolvimento permanente de capacidades e competências, permitindo leituras e consequente informação da situação presente e prospetiva de uma determinada identidade profissional. Se, nos conceitos de profissão e qualificação, os saberes, as competências e as funções estavam definidas e estabilizadas à partida, consistindo o processo de profissionalização, na sua aquisição, construção e desempenho, a profissionalidade remete-nos para a ideia de um processo de reconstrução contínua das identidades profissionais, através de uma reconfiguração dinâmica dos saberes e competências a elas associadas.

Esta (re)configuração sucessiva possível deve ser entendida numa lógica profissional de quem exerce, habitualmente, um agregado coerente de atividades, usa métodos e processos de trabalho com coesão própria, tem uma linguagem específica com ilustrações discursivas, partilhadas e reconhecidas pelos pares, e recebe uma remuneração compatível (Fig. 1), tendo um campo de possibilidades para alargar, reforçar e valorizar o seu estatuto profissional e social comum. Desenvolver profissionalidades apela, por isso mesmo, ao incremento da interação de sujeitos, desafiados a encontrar novas formas coletivas de negociação e de luta por um renovado reconhecimento e valorização social. 


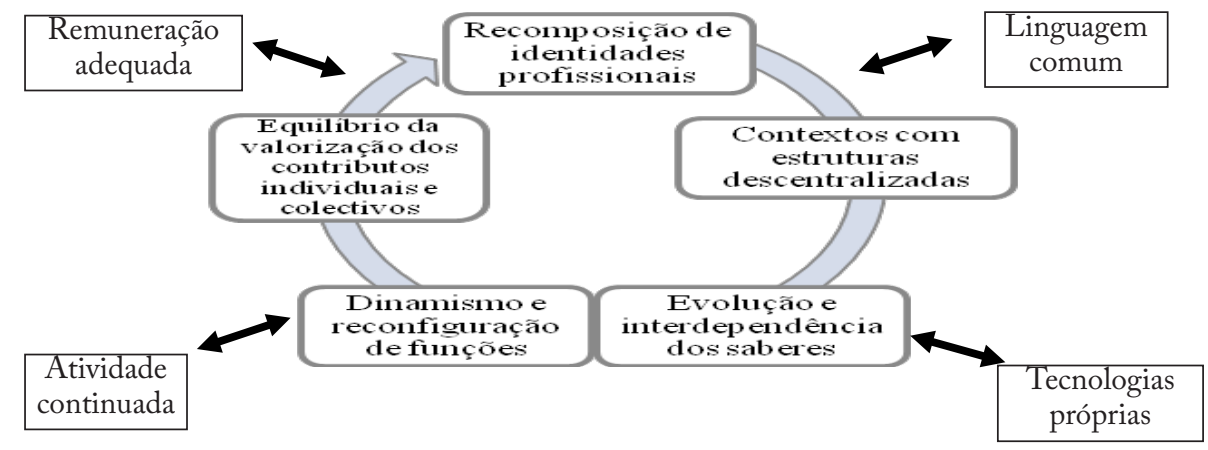

Fig. 1: Ciclo e dimensões de desenvolvimento da Profissionalidade

A profissionalidade necessita, em consequência, de se constituir como a resultante de, pelo menos, duas dimensões principais: as condições intersubjetivas da ação individual e de grupo; a existência de contextos sociopolíticos convocadores de uma ação coletiva de construção de identidades e da sua valorização, nas negociações relativas à organização e ao desenvolvimento do trabalho. No quadro da primeira dimensão, a profissionalidade reporta-se à ação profissional autónoma com caraterísticas identitárias, compreendendo um compromisso ético e político com o trabalho, o desenvolvimento profissional e todos os trabalhadores, com particular destaque para os que partilham o mesmo conjunto de atividades. A segunda dimensão remete para a procura contínua de uma direção politico-ideológica que assente num projeto humanista de valorização das pessoas e dos seus contributos individuais e coletivos. Nestas sociedades ninguém poderá ser apenas um trabalhador treinado para desempenhos profissionais, acríticos e adaptativos, ainda que, sob compromissos obscuros com a competitividade e a produtividade, devendo, pelo contrário, envolver-se num contrato conjunto de construção de comunidades profissionais de bem-estar comum, capazes de evoluir num acordo de procura contínua de responsabilidade e autonomia individual e coletiva.

Em síntese, a profissionalidade docente abre-se como um campo de construção conjunta a partir da cultura acumulada e dos desafios que hoje se colocam aos professores, enquanto membros de comunidade profissional com identidade própria, com a qual se envolvem numa ação política responsável, em busca do poder que lhes permita o controle desejável do exercício da sua atividade. A herança cultural, já estabilizada, permite a consolidação de um conjunto de saberes formalizados que, oriundos de um mundo simbólico próprio, se constituem como um corpus científico que deve ser transmitido nas diferentes ofertas formativas iniciais e continuadas, que as universidades e os centros de formação disponibilizam. No entanto, ao aceitarmos a ideia de profissionalidade na dimensão conceitual em que, aqui foi colocada, especialmente, ao que se refere à sua construção ascendente, a partir da ação, estaremos a admitir a indispensabilidade de fazer emergir, tornar consciente e valorizar todo o conhecimento construído, ou resultante, da ação. 
Os professores serão, neste quadro, sempre entendidos como uma conjugação dinâmica de técnicos especialistas e práticos autónomos e reflexivos (MONTE$\mathrm{RO}, 2001)$, necessitando de associar, ao longo da sua vida profissional, um conjunto de atividades formativas continuadas que ajudem a articular e a potenciar estas duas dimensões mutuamente integradoras. $\mathrm{Na}$ verdade, retomando o que anteriormente ficou dito, como toda a ação concreta, a atividade docente convoca, dinamicamente, para um determinado fim, saberes explícitos, que correspondem a tudo o que é ou pode ser formalizado, através de enunciados ou modos operatórios formalmente descritos e passíveis de uma transmissão articulada em universidades, ou centros de formação, e saberes tácitos que, incorporando, ao mesmo tempo, elementos cognitivos, esquemas, crenças, modelos mentais e elementos técnicos indissociáveis de contextos específicos de ação, reúnem características que os tornam incomunicáveis explicitamente, apesar de se lhes pressentir o efeito diferenciador (MALGLAIVE, 2003). Se pensarmos nas formas de aprendizagem que resultam da forma como estes saberes se articulam com a ação, encontraremos quatro diferentes tipos de aprendizagem (PINEAU, 2001) que se representam na Fig. 2.

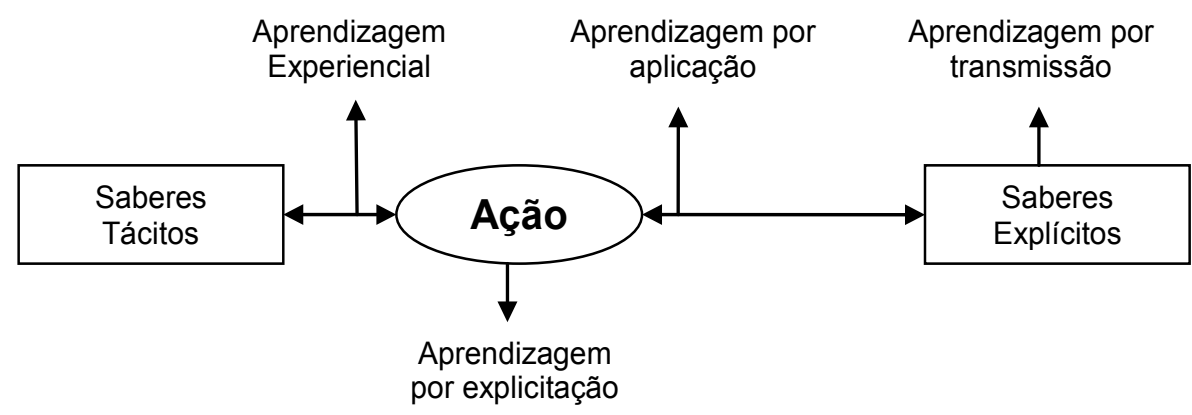

Fig. 2: Relação dos saberes e tipos de aprendizagem com a ação profissional (a partir de PINEAU, 2001)

A aprendizagem experiencial ligada à ação, tal como tinha sido proposto, por exemplo, por Vygotski e Piaget, precede, geneticamente, as outras formas de aprendizagem, mantendo-se ao longo de toda a vida, de maneira a garantir o equilíbrio, ainda que sempre transitório e mutável, entre o sujeito e o contexto. Esta dupla característica, de pedra angular e de efemeridade, tem-lhe vindo a granjear uma importância central como objeto de estudo, nomeadamente para o domínio da educação e formação continuada (cf., por exemplo, KOLB, 1984; SCHÖN, 1983), uma vez que se acredita que apenas pela reflexão e total tomada de consciência da ação, por parte dos sujeitos, pode advir uma significativa transformação dessa mesma ação. As aprendizagens por transmissão e as aprendizagens por aplicação são as que estão ligadas às situações de ensino e formação, "de carácter sistemático, intencional e sequencial" (BOURGEOIS \& NIZET, citados por PINEAU, 2001, p. 341). A aprendizagem por explicitação, por seu lado, introduz uma dimensão reflexiva e de enunciação consciente da aprendizagem anterior. Aprender por explicitação deve resultar, sempre, de uma autoconfrontação cognitiva do(s) sujeito(s) com a sua experiência, por forma a explorar, em análise refletida, todos os saberes envolvidos. Deste confronto, deverá seguir-se, necessariamente, uma (re)construção significativa dos discursos coletivos sobre a ação, proveniente da 
recomposição dos repertórios semióticos, da apropriação de novas formas de mediação e da descoberta de novos quadros teóricos e métodos de trabalho para o investimento e utilização de todos esses novos recursos. Esses processos de reconstrução das ilustrações discursivas, de utilização e reconhecimento comum, podem levar a formas de ilustração da ação que "desbloqueiem" a incompatibilidade genética entre saberes tácitos e saberes explícitos/científicos, criando condições para uma idêntica valorização de todos os tipos de saberes e, através de sua associação identitária, promover contornos mais definidos para o desenvolvimento da profissionalidade.

Uma última palavra, neste ponto do debate, para o tipo de ação que se constata e/ou se deseja no (para o) exercício da profissionalidade dos professores. Desde iniciativas políticas, com destaque para a reunião dos ministros europeus de educação, ocorrida em Helsínquia, em 1987, passando por trabalhos de reflexão e investigação (e.g. FREIRE, 1996; HARGREAVES, 1998; SHULMAN, 1998; PERRENOUD, 2004; ROLDÃO, 2005; SARRAMONA, 2011; RODRIGUEZ, 2011) existe uma preocupação real em contribuir para esclarecer os contextos, os saberes, as competências e as circunstâncias em que os professores devem desenvolver a sua ação, bem como os agentes e instituições com as quais se deve relacionar e de que forma o deve fazer. Não sendo objetivo deste trabalho uma revisão crítica destes (e muitos outros) contributos para um debate necessário, sempre se dirá que existe o denominador predominante de atribuir aos professores a necessidade de uma curiosidade epistemológica, com destaque para o reforço permanente dos saberes disciplinares e pedagógicos, e de uma reflexão crítica sobre as práticas, como forma de reforçar a melhoria contínua e a construção da comunidade profissional que deve servir de base à construção da autonomia e responsabilidade individual e coletiva.

Outros aspetos de configuração mais abrangente, decorrentes de desafios já enunciados, têm vindo a ser, igualmente, trazidos à colação por muitos desses trabalhos. Entre as dimensões mais frequentemente referidas, podem salientar-se a promoção da inclusão, a abordagem intercultural e o respeito pela diversidade, com os saberes que lhe estão associados, prosseguindo uma missão inegociável de promoção de cidadania informada e ativa, como base para o desenvolvimento de comunidades e sociedades sustentáveis. A estas componentes deveremos juntar a necessidade de otimizar a identificação e comunicação com os contextos familiares e os territórios, a diversificação atualizada dos meios e processos de ensino/aprendizagem, com destaque para o uso das tecnologias de comunicação, e o reforço da participação na administração e gestão das organizações e, na elaboração de contributos críticos para as políticas educativas e respectiva execução. Esta junção contínua e indissociável de competências "académicas", competências "pedagógicas"e competências organizacionais/contextuais (SARRAMONA, 2011) são a base de construção da profissionalidade dos professores que, haja vista a possibilidade de mudança sem formação, necessitam de se apoiar em atividades formativas continuadas.

\section{Ação e (trans)formação pessoal e social. Bases para a cons- trução de uma profissionalidade docente}

A questão seguinte remete-nos para a necessidade de encontrar modelos teóricos e práticas formativas que ajudem a construir um sentido desejável, aperfeiçoando a ação e reforçando as condições para o desenvolvimento profissional e a construção da profissionalidade, tal como foi anteriormente entendida. Pelo que ficou dito e pelos 
trabalhos que foram publicados ao longo das últimas décadas (ALCOFORADO, 2008), sabemos que qualquer ação concreta (como a profissional) é sempre situada e, por isso mesmo, depende em cada momento das caraterísticas e recursos dos sujeitos individuais e/ou coletivos que a desenvolvem e das condições dos contextos onde ocorre. Os modelos teóricos especificamente pensados para a formação continuada, cada um com o seu pensamento específico predominante, colocam as suas preocupações ideológicas e tecnológicas (fins e meios) exatamente ao serviço dessa necessidade de analisar e transformar a ação.

Os primeiros quadros teóricos com esta preocupação surgem com influência do pragmatismo americano, retomando o essencial dos contributos pedagógicos veiculados por John Dewey. Em consonância com a sua filiação filosófica no pragmatismo, Dewey enfatizava as bases empíricas do conhecimento, assumindo uma identificação plena entre o método educativo e o método científico, uma vez que ambos deviam implicar uma ação sobre as coisas, uma alteração das condições existentes e uma verificação da consonância, ou da negação, entre essa alteração e as hipóteses formuladas. Havendo a necessidade de evitar que esta construção se revista de uma interpretação excessivamente subjetiva e pessoal, é obrigatório que ela se abra e se confronte com o coletivo que o indivíduo integra, pelo que o processo educativo, de aprendizagem e de desenvolvimento (simultâneo, para Dewey), fica incompleto sem uma interação social, democrática nos princípios teóricos, nos meios e nas finalidades. Como consequência destas orientações gerais, resulta uma defesa da inutilidade de separar a educação liberal da educação profissional, assim como resulta uma opção pela ineficácia da separação e isolamento de qualquer fase ou componente do ato educativo. Ao mesmo tempo, resulta, igualmente claro, que qualquer problema que surja no âmbito de qualquer processo educativo, apenas se poderá resolver pelo aprofundamento e exploração dos princípios e métodos de exercício da democracia.

Apesar de algumas críticas que têm sido aduzidas à abordagem de Dewey à educação, entre as quais ganham particular importância (FINGER\& ASÚN, 2003, p. 41) a perspetiva demasiado filosófica (logo "associológica, aestruturalista, apolítica e não institucional") e a crença absolutista no crescimento e desenvolvimento, as suas propostas tiveram um impacto direto, de grande relevância, nas práticas de formação continuada, mormente através da criação e desenvolvimento da aprendizagem experiencial, cujo grande impulsionador havia de ser David Kolb.

Assumindo a sua teoria, como resultante das contribuições de Dewey e do entendimento da experiência como centro organizador de todos os processos de aprendizagem, de Kurt Lewin e da sua preocupação em integrar teoria e prática e de Piaget, em cuja teoria do desenvolvimento cognitivo procurou a importância da experiência no processo de interação com o meio e os objetos, para a assimilação e acomodação do conhecimento, Kolb (1984) afirma a sua convicção de que o desenvolvimento humano ocorre através da aprendizagem pela experiência, constituindo-se esta, como a unidade de análise decisiva na compreensão e consolidação das relações entre o trabalho, o desenvolvimento pessoal e a formação. Kolb (1984, p. 20-21) enuncia que não pretende afirmar a aprendizagem experiencial como uma alternativa às teorias de aprendizagem existentes (racionalistas e outras propostas cognitivistas), ambicionando, tão-somente, sugerir "através da aprendizagem experiencial, uma perspetiva holística e integradora, que combina experiência, perceção, cognição e comportamento". 
Desenvolvimento profissional,profissionalidade e formação continuada de professores: possíveis contributos dos relatos autobiográficos profissionais

Entendendo, então, a aprendizagem como um processo dialético que integra experiência e conceitos, observações e ação, Kolb (1984) propôs a leitura do processo de aprendizagem ao longo de um ciclo sequencial de mobilização de quatro funções: experiência concreta, observação reflexiva, conceptualização abstrata e experimentação ativa, sendo que a aprendizagem é sempre o resultado da combinação obrigatória de todas elas, resultando de uma adaptação holística ao mundo e implicando a existência de transações entre o indivíduo e o meio.

Ainda, com uma filiação teórica no pragmatismo e trabalhando sobre bases teóricas idênticas, adaptadas à gestão e ao comportamento organizacional, Argyris \& Schön (1974; 1978) e Argyris (1998), propuseram um modelo de aprendizagem que se afasta da proposta de Kolb, na medida em que sugerem ser possível alterar os pressupostos da ação, sem passar pela fase da experimentação ativa. Em síntese, estes autores defendem que todos nós, ao agirmos, usamos teorias orientadoras, que designam de teorias da ação, ${ }^{2}$ as quais podem ser de duas naturezas diferentes: as primeiras designadas de teorias-em-uso, que são implícitas à ação, estando para ela numa relação como a da gramática, em uso, está para o discurso, ao mesmo tempo que contêm hipóteses sobre a identidade pessoal, os outros e os contextos, sendo, por isso mesmo, potenciadas, ou condicionadas, pelo poder dessas hipóteses; as segundas denominadas de teorias assumidas, expressas pelas palavras que usamos para transmitir o que fazemos, ou, o que queremos que os outros pensem que nós fazemos. Então, para aprender, não é obrigatório passar por uma fase de ensaios e erros, propondo a possibilidade de uma aprendizagem mais significativa, refletindo criticamente sobre as teorias da ação. A esta proposta chamam Argyris \& Schön (1978) aprendizagem de duplo ciclo, por oposição à designada aprendizagem de ciclo único, a qual não inclui esta reflexão crítica, optando por uma passagem imediata para a experimentação ativa. Em termos práticos, tudo se passa como se no ciclo de Kolb, a fase de conceptualização abstrata passa a incorporar um novo ciclo de reflexão crítica sobre as teorias da ação, dando lugar, não à experimentação ativa, mas a uma ação real mais esclarecida, autónoma e responsável.

Um tal entendimento da aprendizagem altera, de maneira substancial, quer o papel do formador, quer da organização da formação. $\mathrm{Na}$ aprendizagem de duplo ciclo, os formadores (mediadores ou orientadores) confrontam os indivíduos com a congruência (ARGYRIS\& SCHÖN, 1974) entre as teorias-em-uso e as teorias assumidas, refletindo sobre a eficácia da ação e a validade dos resultados, para empreenderem um questionamento da consistência interna de todas as variáveis e valores que determinam a ação. Mais que agir e refletir para voltar a agir, como propunha, Argyris \& Schön (1974) propõem que os indivíduos sejam incentivados a enunciarem as suas teorias da ação, para, a partir daí, poderem reequacionar e, eventualmente, reformular todos os seus pressupostos.

Finger \& Asún (2003) integram, igualmente, no âmbito das ideias passíveis de ser incluídas na influência teórica do pragmatismo, com impacto na formação continuada, alguns dos contributos do interacionismo simbólico, mormente os trabalhos de Herbert Mead e Peter Jarvis, afirmando que "o interacionismo simbólico é basicamente a aplicação do pragmatismo ao reino da linguagem, isto é, da interação humana simbólica" (FINGER\& ASÚN, 2003, p. 50). Vivendo num universo exclusivamente simbólico, os seres humanos vão interpretando as suas relações e interações em função de um simbolismo construído, contribuindo para o desenvolvimento da identidade global do grupo ou comunidade que integram, ao mesmo tempo que consolidam a sua 
identidade (self para Mead ou pessoa para Jarvis), a qual tem, desta forma, uma dimensão, simultaneamente individual e social. Para os autores referidos, o que o interacionismo simbólico propõe é uma adaptação do ciclo de aprendizagem experiencial de Kolb a um ambiente simbólico, entendendo que a aprendizagem na idade adulta não conduz exclusivamente à construção de novos conhecimentos, capacidades e atitudes, para participar no desenvolvimento da comunidade, mas é sempre entendida como um meio de autodesenvolvimento da identidade. Também, neste caso, fala-se de uma disjunção entre a imagem que é apresentada a terceiros e a imagem que estes têm do sujeito, ou, dito de outra forma, entre a biografia e a experiência. Nesta discrepância reside, segundo esses modelos, a base do processo de aprendizagem, assim como o seu impulso mais decisivo.

Um segundo conjunto de propostas tem por base o pensamento de Abraham Maslow e Carl Rogers, dois dos nomes que marcaram o humanismo moderno, nomeadamente o campo da psicologia, mas com influência decisiva no domínio da educação e da formação. Ambos tinham em comum uma conceção otimista e positiva acerca da pessoa humana, sobre a qual defendem que possui uma forte e contínua motivação para a aprendizagem e a mudança, que lhe advém "da tendência da própria vida para se atualizar e da tendência do organismo para percorrer os diferentes canais do desenvolvimento potencial, na medida em que podem ser experimentados como favorecendo o crescimento" (ROGERS, 1984, p. 258). Partindo da sua experiência como psicoterapeuta, este autor defende a ocorrência de aprendizagem significativa, com consequente alteração estável do self, sempre que as situações educativas são assumidas, pelos sujeitos, como problemáticas e se desenvolvem num ambiente favorável, encorajador, de forte empatia e de aceitação e compreensão mútua com o professor, entendido como um facilitador ou orientador da aprendizagem, a qual, por sua vez, é entendida como um processo completamente interno e controlado pelo sujeito (ROGERS, 1984).

Por seu lado, Maslow (1970) defende que a aprendizagem é motivada pela satisfação de necessidades, sendo que, ao propor a sua disposição numa pirâmide hierárquica, conclui que: à medida que as necessidades básicas vão sendo atendidas, vão emergindo outras de nível superior, culminando com o aparecimento de uma necessidade contínua de auto-atualização e autodesenvolvimento. Em consequência, podemos concluir, quer do pensamento de Carl Rogers, quer dos contributos de Abraham Maslow, o entendimento da pessoa humana como envolvida numa procura contínua de autonomia, liberdade, auto-atualização e auto-direção, como única forma de se tornar totalmente funcional. Daqui resulta um entendimento de educação e, por maioria de razão, de formação continuada, como uma proposta não diretiva de facilitação da aprendizagem, criando as melhores condições para o desenvolvimento e autorrealização de cada pessoa, acreditando, por esta via, na promoção do desenvolvimento pessoal e social, rumo a situações sucessivas de bem-estar.

É este conjunto de contributos que impele Malcolm Knowles a propor o modelo andragógico como base para as atividades educativas para adultos, afirmando a sua convicção de que um indivíduo se torna adulto, quando se percebe a si mesmo como autodirigido, sendo capaz de, num ambiente favorável, utilizar todo o seu capital de experiência para empreender mudanças significativas na sua vida, despoletadas por um processo de motivação intrínseca. 
Por fim, um último conjunto de contributos acaba por encontrar no programa epistemológico proposto por Jürgen Habermas a sua principal justificação teórica. Ao envolver-se na procura de uma epistemologia alternativa a positivista, baseando-a no princípio da pluralidade de tipos de conhecimento, cada um com as suas caraterísticas próprias, Habermas propõe (ALCOFORADO, 2012) que a construção do saber é resultado da atividade humana, motivada por necessidades e interesses, conduzindo à construção de um programa epistemológico, constituído por três formas diferentes, mas igualmente legítimas, de encarar a vida social: as ciências empírico-analíticas, cujo interesse é técnico, de predição e controlo dos fenómenos naturais, pretendendo estabelecer verdades universais, através da procura da objetividade e da neutralidade, organizando-se em torno de uma racionalidade instrumental; as ciências histórico -hermenêuticas, cujo interesse reside na interpretação e compreensão, desenvolvendo significados para uma vida comum e partilhada, através de uma racionalidade comunicativa; as ciências críticas, trabalhando numa racionalidade transformativa e emancipatória, comprometida com a autonomia e a libertação dos seres humanos, aspirando a envolvê-los numa ação comunicativa sem qualquer tipo de coações ou dominações.

Nessa linha de pensamento, qualquer ciência social ou humana deve ser uma ciência crítica, comprometendo-se com as pessoas e os seus grupos de pertença na remoção dos poderes e interesses que criam obstáculos a uma cidadania plena, com igualdade de direitos, oportunidades e deveres. Para isso, é fundamental que nos envolvamos em processos de aprendizagem emancipatória, construindo um conhecimento resultante da autorreflexão crítica, traduzido pela maneira como contamos a nossa história ou biografia, como nos vemos, como estruturamos as nossas conceções sobre a aprendizagem e a natureza do conhecimento e pela maneira como construímos as nossas expectativas, bem como os diferentes entendimentos e sentimentos que influenciam o desempenho dos nossos papéis sociais. Esta reflexão crítica, ou aprendizagem emancipatória, deverá promover uma "emancipação de forças libidinais, linguísticas, epistémicas, institucionais e de condicionantes contextuais, as quais limitam as nossas opções e o controlo racional sobre as nossas vidas" (MEZIROW, 1991, apud ALCOFORADO, 2012). Tal reflexão implica, naturalmente, o questionamento crítico de ideias erradas, ideologias e distorções psicológicas, resultantes de aprendizagens anteriores que produziram, ou perpetuaram, relações não identificadas de dependência.

Em síntese, destas três perspetivas teóricas revistas poderemos retirar outros tantos contributos complementares entre si, que serão fundamentais incluir em qualquer processo de formação continuada e desenvolvimento profissional: a necessidade de analisar e refletir criticamente sobre a ação; a obrigação de construir ambientes favoráveis e o crédito que a partir de motivações intrínsecas, as pessoas têm dentro de si próprias tudo o que é necessário para empreender as mudanças necessárias; todas as atividades de formação continuada devem ter uma dimensão emancipatória, promovendo uma libertação e uma autonomia responsável face a forças ambientais condicionadoras.

O ponto central do nosso debate, nesse texto, é que sobre certas condições, os relatos autobiográficos profissionais podem reunir essas caraterísticas, contribuindo para, numa formulação freireana, pensar a possibilidade de uma pedagogia dos professores para a formação continuada. Vamos muito brevemente refletir sobre essas condições. 


\section{Possíveis contributos dos relatos autobiográficos profissionais}

No final do século passado, Nóvoa (1997) falava de um novo movimento "ainda de contornos mal definidos" que se manifestava "através da procura de uma nova epistemologia da formação, tendo como expressões visíveis, por exemplo, as experiências em torno das histórias de vida e do método (auto)biográfico". Uns anos mais tarde, Josso (1999) e Pineau (2006) ajudavam-nos a fazer uma sutil distinção entre algumas das diferentes expressões que apareciam associadas a esse movimento. A primeira autora falava de histórias de vida como projeto de conbecimento e histórias de vida a serviço de projetos, para distinguir relatos da totalidade da vida e relatos centrados num determinado aspecto, com o objetivo de disponibilizar informação adequada para a elaboração de um determinado projeto. Por seu lado, o segundo autor dizia-nos que as histórias de vida obrigavam a uma construção de sentido temporal sem um julgamento prévio dos meios, enquanto os relatos de vida apontam para a importância da expressão do vivido pelo desdobrar narrativo, quer essa enunciação seja oral ou escrita.

De comum, todos estes métodos se baseiam no princípio de que é sempre a própria pessoa que, ao elaborar uma compreensão (sobre a totalidade ou parte) do seu percurso de vida, forma-se e, ao ganhar consciência do processo e das condições de construção de seu conhecimento, desenvolve uma completa implicação pessoal nesse mesmo processo, podendo imprimir uma continuidade temporal no presente e fazendo a sua projeção no futuro. Esse trabalho hermenêutico, simultaneamente retrospetivo e prospetivo, sustenta-se na convicção de que a aprendizagem não reside somente nos saberes disciplinares exteriores à pessoa, mas também no conhecimento de si própria, elegendo como recursos educativos, as experiências de vida, as histórias vividas e as heranças sociais e culturais de todos os envolvidos num processo de educação/formação, e em percursos profissionais. Toda esta diversidade de métodos e de aplicações - histórias de vida singulares, coletivas, genealógicas e profissionais - bem como o suporte empírico que vão reunindo, nomeadamente a sua utilização, enquanto prática de formação com pessoas adultas, foram-nas remetendo para o estatuto de uma justificada esperança e fundamentada expectativa, no desenvolvimento de um quadro teórico e de um campo de práticas específico para a formação continuada.

De todas essas propostas, para o que aqui nos interessa, vamos ocupar-nos brevemente sobre o que designaremos de relatos autobiográficos profissionais. Assume-se esta utilização como um método adequado para a produção de conhecimento sobre temas ou situações específicas, relativas às atividades ligadas ao trabalho, utilizando relatos num processo em que profissionais se reúnem, num contexto de formação, envolvendo-se, voluntariamente, num questionamento pessoal, procurando a relação entre a sua experiência e o seu desejo de aprender, explorando elementos constitutivos dos seus percursos, para, de seguida, organizar uma narrativa escrita ou oral esforçando-se por responder aos seus questionamentos iniciais, com a ajuda de um grupo de pares (LAINÉ, 2000) e de um mediador, trabalhando segundo um modelo interativo ou dialógico, organizado numa relação entre sujeitos e mediador, em busca de uma co-construção de sentido, acreditando que este não se poderá reduzir, nem à consciência dos autores, nem à análise dos sujeitos e do mediador que acompanham este processo(PINEAU, 2006). 
Em síntese, os relatos autobiográficos profissionais, desenvolvidos de acordo com esta proposta dialógica, ambicionarão primeiro, afirmar-se como uma prática formativa que consubstancia a criação de condições ambientais propícias para despoletar a mudança profissional, depois, potenciar a compreensão de que os sujeitos são, em si mesmos, na ação, ou seja, no modo como se relacionam com os outros, os objetos e os contextos (ALCOFORADO, 2012) e, por fim, despoletar projetos gnosiológicos grupais de futuro (JOSSO, 2002), capazes de problematizar a realidade sócio-históri$\mathrm{ca}$, alterando as condições de exercício da atividade profissional com maior autonomia e responsabilidade. Esclarecido, dessa forma, o essencial da dimensão ideológica desta prática formativa, procuremos agora contribuir para clarificar a dimensão metodológica do seu desenvolvimento. ${ }^{3}$

Correspondendo às questões centrais, colocadas pelos modelos humanistas, a preocupação inicial deverá orientar-se para esclarecer a necessidade de mudança, face a problemas profissionais bem identificados, envolvendo volitivamente os sujeitos num processo de procura de melhores soluções para a transformação a empreender. Suportando-nos, assim, na ideia central do pensamento rogeriano, devemos conceder um crédito ilimitado à possibilidade de aperfeiçoamento contínuo da condição humana, a partir de situações de relacionamento interpessoal, desde que sejam observadas, nessa relação, as seguintes condições: partir da necessidade de fazer face a um problema; basear-se em comportamentos integrados e congruentes; partir sempre de uma consideração positiva incondicional; basear-se na criação de uma situação empática. Em consonância com estes princípios, a prática formativa dos relatos autobiográficos profissionais deve desenvolver-se a partir de pequenos grupos, integrado voluntariamente por pessoas com identificação de problemas profissionais semelhantes e vontade de mudança comum, onde se constrói um ambiente potenciador de auto e hétero confiança.

A segunda fase incluirá a expressão do vivido, o relato oral das experiências profissionais, incentivando os participantes a enunciar a sua ação (o que fizeram? porque fizeram? como fizeram?), refletindo criticamente sobre os pressupostos, as razões e as condições contextuais em que a experiência foi desenvolvida. Todos devem participar numa mediação destinada a desdobrar a narrativa, procurando uma descrição circunstanciada da ação, com recurso sistemático a formulações diretas positivas. Após este trabalho de relato oral, os sujeitos assumirão a tarefa de o transformar em escrita, num exercício individual e solitário, aceitando que "a escrita é a plena manifestação do discurso" em que a dialética do evento e da significação "se torna óbvia e explícita" (RICOEUR, 2005, p. 42). A partir destes trabalhos escritos, deverá ser empreendido um exercício de caraterização identitária (herdada, assumida, atribuída, visada...) individual e coletiva, reintegrando o conhecimento de si no jogo de semelhanças e diferenças provocadas pela comparação entre as diferentes narrativas (JOSSO, 2002). Este exercício hermenêutico de análise conjunta dos textos deverá propor-se, como sugere Bakhtin (1993), à reconstrução dialógica de signos, enunciados e discursos, numa articulação entre o estilo individual da ação e do discurso e o gênero profissional coletivo, incrementando as expressões de significado comum. O objetivo central deverá pautarse pela tomada de consciência sobre os diferentes mundos profissionais, individuais e coletivos, com os saberes, os valores, os referenciais, a linguagem e os métodos de trabalho específicos, visando o nível de mestria desejado para a autorrealização profissional e a definição de condições para a clarificação dos contornos da profissionalidade. 
Assumimos, então, os relatos autobiográficos profissionais como uma prática transformativa que, mais que colocar o seu interesse na descrição de um passado (re)presentificado, contribua para a libertação das alternativas que foram sendo escondidas pela ordem dos acontecimentos (ALCOFORADO, 2012), ajudando a resolver a tensão entre as expectativas e os constrangimentos e otimizando as possibilidades de transformar (dizendo, pensando e agindo) o que tem sido a história de cada pessoa e de cada grupo profissional. Estaremos, desta forma, a identificar esta prática formativa como uma atividade propiciadora de aprendizagens emancipatórias, as quais devem dar sentido a um projeto realista e desafiador de mudança do trabalho e das condições nas quais ele decorre.

\section{Conclusão}

Os estudos que têm sido realizados sobre a formação continuada de professores, em Portugal (ESTRELA et al., 2005, p.139), vêm mostrando a necessidade de repensar fazendo com que integre "um neo-humanismo, a configurar-se a partir do paradigma da alteridade, onde todos se assumem de forma dialógica e comunicacional”, favorecendo "a investigação, a prática reflexiva e a profissionalização interativa, estimulando a sinergia das competências profissionais de todos os intervenientes". Recorrendo ao conhecimento acumulado no âmbito das ciências da formação, e que aqui revisitamos sinoticamente, será possível configurar uma prática formativa que, fundamentada em modelos teóricos robustos, possa responder a esta necessidade. Estes eventuais contributos dos relatos biográficos profissionais, com os contornos teóricos e operacionais que foram desenhados, não estarão a coberto de algumas limitações, mas sugerem uma atratividade que valerá a aposta de uma utilização crescente. Será uma metodologia demorada, com exigência de domínio de conhecimentos multidisciplinares e transdisciplinares complexos, mas que poderá responder à necessidade da construção participada da profissionalidade dos professores, tornando consciente as transformações e imobilidades caraterísticas do desenvolvimento profissional, através de uma reflexão crítica das práticas, tudo isto com base numa relação dialógica promotora de uma formação emancipatória.

\section{Referências}

ALCOFORADO, L. As Histórias de Vida na Educação e Formação de Adultos: o desafio de promover uma auto(eco)confrontação transformativa e emancipatória. In: J. L. Cunha e P. P. Vicentini, Pesquisa (Auto)Biográfica, Temas Transversais. Corpos, saúde, cuidados de si e aprendizagens ao longo da vida: desafios (auto)biográficos, Natal, Porto Alegre, Salvador: EDUFRN, ediPUCRS, EDUNEB, 2012, p. 29-54).

Competências Cidadania e Profissionalidade. Limites e desafios para a construção de um modelo português de educação e formação de adultos. Tese de Doutoramento. Coimbra: Faculdade de Psicologia e de Ciências da Educação da Universidade de Coimbra, 2008.

ARGYRIS, C. Knowledge for action. San Francisco: Jossey-Bass, 1998.

ARGYRIS, C; CHÖN, D. Organizational Learning: a theory of action perspective. Reading: Addison-Wesley, 1978. 1974.

Theory in practice. Increasing professional effectiveness. San Francisco: Jossey-Bass,

BAKHTIN, M. M. Toward a philosophy of the act. Austin: University of Texas Press, 1993. 
Desenvolvimento profissional,profissionalidade e formação continuada de professores: possíveis contributos dos relatos autobiográficos profissionais

BALTES, P. B. Theoretical propositions of life-span developmental psychology: on the dynamics between growth and decline, Development Psychology, 23, p. 611-626, 1987.

CORDEIRO, A. R., ALCOFORADO, L.; FERREIRA, A. G. Projeto Educativo Local. Um processo associado a estratégias de desenvolvimento integrado e sustentável. Cadernos de Geografia, 30/31, p. 313-324, 2012.

COURTOIS, B. Transformations de la formation et recompositions identitaires en entreprise. In: J. M. BARBIER, F. BERTON \& J. J. BORU, Situation de travail et formation, Paris: L'Harmattan, 1996.

DUBAR, C. A Socialização, Construção das Identidades Sociais e Profissionais. Porto: Porto Editora,1997.

ESTEVE, J. M. Latercerarevolución educativa, Barcelona, Paidós, 2003.

ESTRELA, A., ELISEU, M., AMARAL, A., CARVALHO, A.; PEREIRA, C. A Investigação sobre a Formação Contínua de Professores em Portugal (1990 - 2004). Investigar em Educação, 4, 2005, p. 107-148.

ESTRELA, T. Dimensões burocráticas do trabalho docente. In: Atas do XI Congresso da Sociedade Portuguesa de Ciências da Educação, Guarda: Instituto Politécnico da Guarda, 2011, p. 1-6.

FINGER, M.; ASÙN, J. M. A Educação de Adultos numa Encruzilhada. Aprender a nossa saída. Porto: Porto Editora, 2003.

FREIRE, P. Pedagogia da Autonomia. Saberes necessários à prática educativa. São Paulo: Paz e Terra, 1996.

HARGREAVES, A. Os professores em tempos de mudança - o trabalho e a cultura dos professores na idade pós-moderna. Lisboa: McGraw Hill,1998.

JOSSO, M. C. Histórias de Vida e Formação. Lisboa: Educa, 2002.

. História de vida e projeto: a história de vida como projeto e as "histórias de vida" a serviço de projetos. Educação e Pesquisa, São Paulo, v. 25, n. 2, p. 11-23, 1999.

KOLB, D. Experiential Learning: experience as the source of learning and development. Englewood Cliffs: Prentice Hall, 1984.

LAINÉ, A. Savoir, apprendre, se former. La perspective de l'histoire de vie. VEI Enjeux, 123, p. 176-194, 2000.

LÜDKE,M.; BOING,L. A. Caminhos da Profissão e da Profissionalidade Docentes. Educação e Sociedade, v. 25, n. 89, p. 1159-1180, 2004.

MAGLAIVE, G. Ensinar Adultos. Porto: Porto Editora, 2003.

MARCELO, C. Desenvolvimento Profissional Docente: passado e futuro. Sísifo- Revista de Ciências da Educação, n. 8, 2009.

MASLOW, A. Motivationand Personality. Nova Iorque: Hasper\&Row, 1970.

MONTERO, L. A construção do conhecimento profissional docente. Lisboa: Instituto Piaget, 2005.

MORIN, E. Os sete saberes para a educação do futuro. Lisboa: Instituto Piaget, 2002.

NÓVOA, A. Histórias de Vida. In: Departamento da Educação Básica. Educação de Adultos. Lisboa: DEB, 1997, p. 58-69,

PERRENOUD, PH. Diez nuevas competencias para enseñar, Barcelona, Graó, 2004. 
PINEAU, G. As histórias de vida em formação: gênese de uma corrente de pesquisa-ação-formação existencial. Educação e Pesquisa, v. 32, n. 2, 329-343, 2006.

. Experiências de Aprendizagem e Histórias de Vida. In: P. CARRÈ.; P. CASPAR, Tratado das Ciências e Técnicas da Formação, Lisboa: Instituto Piaget, p. 327-348, 2001.

RICOEUR, P. Teoria da Interpretação. O discurso e o excesso de significação.Lisboa: Edições 70, 2005.

RODRIGUEZ, J. M. M. Función Docente y Sociedad. Limites y Oportunidades del Maestro. Revista Portuguesa de Pedagogia, Extra-Série, p. 385-400, 2011.

ROGERS, C. Tornar-se Pessoa. Lisboa: Moraes, 1984.

ROLDÃO, M. C. N. Profissionalidade Docente em Análise: especificidades do ensino superior e não superior. Nuances: estudos sobre educação, ano XI, 12/13, 2005.

SARRAMONA, J. Que Significa ser Profissional Docente enlaActualidad?. Revista Portuguesa de Pedagogia, Extra-Série, 427-440, 2011.

SCHÖN, D. The Reflexive Practitioner. New York, 1983.

Notas

${ }^{1}$ Profissionalidade é ainda um neologismo (não consta dos diversos dicionários de língua portuguesa consultados), que veio do italiano (profissionalità), através do francês (professionnalité). Este conceito foi utilizado pelos sindicatos da Itália, numa altura em que pretendiam reivindicar o reconhecimento dos saberes da experiência como desenvolvimento do modelo da qualificação.

${ }^{2}$ Theories of action, no original, entendidas como "mental maps with regard to how to act in situations... this involves the way they plan, implement and review their actions" (ARGYRIS \& SCHÖN, 1974, pp. 4-5). Os mesmos autores defendem que estas teorias se distinguem em dois tipos diferentes e constratantes de teorias: "theories-in-use" e "espoused theories". Optamos por traduzi-las, respetivamente, por teorias-em-uso e teorias declaradas. Argyris (1993, p. 1-2) empreende um maior esclarecimento sobre este entendimento de ação, relacionando-a conceitualmente com ideias como "action is how we give meaning to life...the word action conjures up images of individuals doing, executing, and implementing... action is not simply the discovery of new ideas or the development of new policies, it is the implementation of these ideas or policies and the evaluation of the implementation's effectiveness".

${ }^{3}$ Temos vindo a desenvolver o essencial desta metodologia, quer no âmbito dos cursos de pós-graduação em Ciências da Educação da Faculdade de Psicologia e de Ciências da Educação da Universidade de Coimbra, quer no âmbito de uma ação de formação continuada de professores e de formadores de adultos que decorreu com a nossa coordenação pedagógica, mas organizada por um centro de formação de professores de uma associação de escolas.

* Professor Doutor da Faculdade de Psicologia e de Ciências da Educação, Universidade de Coimbra, Coimbra - Purtugal. 
Desenvolvimento profissional,profissionalidade e formação continuada de professores: possiveis contributos dos relatos autobiográficos profissionais

\section{Correspondência}

Luís Alcoforado - Faculdade de Psicologia e de Ciências da Educação, Universidade de Coimbra. Rua Colégio Novo, CEP: 3001-802, Coimbra, Portugal.

Recebido em 13 de outubro de 2013

Aprovado em 18 de novembro de 2013 
